\title{
Development of a Multiplex Bead Assay for Simultaneous Serodiagnosis of Antibodies against Mycobacterium bovis, Brucella suis, and Trichinella spiralis in Wild Boar
}

\author{
Antonia Touloudi ${ }^{1}$, George Valiakos ${ }^{1}$ D , Shaun Cawthraw ${ }^{2}$, Polychronis Kostoulas ${ }^{1,3}$ (D), Christian Gortázar ${ }^{4}$, \\ Mariana Boadella ${ }^{5}$, Alexios Giannakopoulos ${ }^{1}$, Periklis Birtsas ${ }^{6}$, Marina Sofia ${ }^{1}$, Labrini V. Athanasiou ${ }^{1} \mathbb{D}$, \\ Maria Satra ${ }^{3}$, Zoi Athanasakopoulou ${ }^{1}$, Maria Kantere ${ }^{1}$, Vassiliki Spyrou ${ }^{7}$, Liljana Petrovska ${ }^{2}$ \\ and Charalambos Billinis 1,3,*(D)
}

check for updates

Citation: Touloudi, A.; Valiakos, G.; Cawthraw, S.; Kostoulas, P.; Gortázar, C.; Boadella, M.; Giannakopoulos, A.; Birtsas, P.; Sofia, M.; Athanasiou, L.V.; et al. Development of a Multiplex Bead Assay for Simultaneous Serodiagnosis of Antibodies against Mycobacterium bovis, Brucella suis, and Trichinella spiralis in Wild Boar. Microorganisms 2021, 9, 904 . https://doi.org/10.3390/ microorganisms 9050904

Academic Editor: Hirokazu Kimura

Received: 27 March 2021

Accepted: 20 April 2021

Published: 23 April 2021

Publisher's Note: MDPI stays neutral with regard to jurisdictional claims in published maps and institutional affiliations.

Copyright: (c) 2021 by the authors. Licensee MDPI, Basel, Switzerland. This article is an open access article distributed under the terms and conditions of the Creative Commons Attribution (CC BY) license (https:/ / creativecommons.org/licenses/by/ $4.0 /)$.
1 Faculty of Veterinary Science, University of Thessaly, 43100 Karditsa, Greece; atoul@uth.gr (A.T.); georgevaliakos@uth.gr (G.V.); pkost@uth.gr (P.K.); algiannak@uth.gr (A.G.); msofia@uth.gr (M.S.); lathan@uth.gr (L.V.A.); zathanas@uth.gr (Z.A.); mkantere@uth.gr (M.K.)

2 Animal and Plant Health Agency, Addlestone KT15 3NB, UK; Shaun.Cawthraw@apha.gsi.gov.uk (S.C.); Liljana.Petrovska@apha.gsi.gov.uk (L.P.)

3 Faculty of Public and Integrated Health, University of Thessaly, 43100 Karditsa, Greece; msatra@med.uth.gr

4 SaBio, Instituto de Investigación en Recursos Cinegéticos IREC, 13005 Ciudad Real, Spain; Christian.Gortazar@uclm.es

5 SABIOTEC, Camino de Moledores s/n, 13005 Ciudad Real, Spain; mariana.boadella@gmail.com

6 Faculty of Forestry, Wood Science and Design, 43100 Karditsa, Greece; birtsas@uth.gr

7 Faculty of Animal Science, University of Thessaly, 41222 Larissa, Greece; vasilikispyrou@uth.gr

* Correspondence: billinis@uth.gr

Abstract: The aim of this study was to evaluate the diagnostic performance of a multiplex bead assay for the simultaneous detection of antibodies against Mycobacterium bovis, Brucella suis, and Trichinella spiralis. Sera from Eurasian wild boar of known serological status for TB (64 seropositive, 106 seronegative), Brucella (30 seropositive, 39 seronegative), and Trichinella (21 seropositive, 97 seronegative) were used for the development and evaluation of the assay. Magnetic beads coated with recombinant MPB83 antigen (TB), a whole-cell B. suis 1330 antigen, and an E/S T. spiralis antigen were used for the detection of specific antibodies using Bio-Rad Bio-Plex technology. The sensitivities (Se) and specificities (Sp) of the multiplex assay were, for M. bovis, 0.98 and 0.86; for B. suis, 1.00 and 0.97; and for T. spiralis, 0.90 and 0.99 (Se and Sp, respectively). The results show the diagnostic potential of this assay for the simultaneous detection of antibodies against M. bovis, B. suis, and T. spiralis in wild boar.

Keywords: multiplex bead assay; Mycobacterium bovis; Brucella suis; Trichinella spiralis; wild boar; serological assay

\section{Introduction}

Mycobacterium bovis, Brucella suis, and Trichinella spiralis are among the zoonotic pathogens transmitted from animals, including wildlife, to humans. Wild boar represent a major reservoir and a potential source of infection among species [1]. This significant role of wild boar has been well documented with the isolation of matching strains of $M$. bovis, the causative agent of bovine tuberculosis from wild boar and cattle [2-4]. Moreover, from the zoonotic point of view, contact with infected animals is a well-known transmission route, evidenced in humans at great risk, associated with professional or leisure activities, such as veterinarians and hunters [5]. Likewise, certain B. suis biovars have been reported in domestic pigs and their wild counterparts, the wild boar, as well as, to a lesser but considerable extent, in human infections [6-9]. Finally, regarding T. spiralis, the application of eradication programs contributed to the reduction of the infection rate, notably in areas with low population density of wild boar, suggesting their key role in the maintenance 
and spread of T. spiralis [10]. The involvement of wild boar in human trichinellosis is further supported by the association between human cases and the consumption of raw or undercooked wild and home-raised game meats, including the wild boar [11].

The diagnosis of bovine tuberculosis is commonly performed by employing the tuberculin skin test using a purified protein derivative, a method based on the triggering of a delayed-type hypersensitivity reaction in infected animals. Despite its popularity, there are certain drawbacks to the use of this method from the practical point of view, mainly the handling of each animal twice in $72 \mathrm{~h} \mathrm{[12],} \mathrm{as} \mathrm{well} \mathrm{as} \mathrm{poor} \mathrm{test} \mathrm{performance,} \mathrm{specifically}$ low specificity [13], and a time period of 2-3 months needed to elapse between tuberculin skin test performance and application of confirmatory tests. Consequently, this test is not only impractical to perform in wild animal species, but also inadequate to provide reliable results due to its poor performance and the need for confirmatory tests, a time-demanding procedure that may contribute to an augmented risk of disease spread [14].

Serology has been applied in the diagnosis of porcine brucellosis, including different diagnostic modalities, such indirect, blocking, and competitive enzyme-linked immunosorbent assays (ELISAs) based on smooth lipopolysaccharide (sLPS) antigens, the Rose Bengal test (RBT), the complement fixation test (CFT), and the fluorescence polarization assay [8].

The diagnosis of swine and wild boar trichinellosis includes both direct methods for the detection of parasite larvae and indirect methods for the evaluation of exposure by the detection of antibodies. The former include trichinoscopy and muscle digestion, which is considered the most reliable postmortem diagnostic method. The latter are also commercial ELISAs available for the detection of antibodies against $T$. spiralis in serum and meat juice of swine, wild boar, and horses. They are typically based on the use of excretory-secretory (E/S) antigens, which are metabolic products of T. spiralis larvae.

All the above-mentioned serological methods are used for the detection of antibodies against each of the three pathogens, M. bovis [15], B. suis [9,16], and T. spiralis, alone in wild boar, which is time-consuming and demands a certain volume of sample. A multiplex assay for the simultaneous detection of antibodies against these pathogens in wild boar would be a useful screening tool. The aim of the study was to develop and evaluate a multiplex bead assay for the simultaneous detection of antibodies against $M$. bovis, B. suis, and T. spiralis in wild boar sera. The multiplex bead assay was based on the Bio-Rad Bio-Plex system of a multi-analyte suspension array, which is based on Luminex's xMAP technology.

\section{Materials and Methods}

\subsection{Serum Samples}

Sera from Eurasian wild boar were used for the evaluation of the multiplex assay. For the TB assay, 64 seropositive and 106 seronegative animals from Spain were tested. For Brucella, 30 seropositive and 39 seronegative Spanish boar were used. The serological status of these animals was determined previously using validated ELISAs [9,17]. For trichinellosis, 21 positive and 97 negative sera from Spanish and Greek wild boar were used for assay development. These had been tested by a commercial ELISA (IDEXX Trichinellosis $\mathrm{Ab}$ Test) for the detection of antibodies against $T$. spiralis as a gold standard test.

\subsection{Multiplex Bead Assay}

The Bio-Rad Bio-Plex multi-analyte bead suspension array system, which is based on Luminex's xMAP technology, was used for the assay. The antigens used were (a) a recombinant MPB83 antigen (Lionex Diagnostics and Therapeutics $\mathrm{GmbH}$, Braunschweig, Germany) for the detection of antibodies against M. bovis, (b) a noncommercial wholecell preparation of the smooth B. suis 1330 that was grown on serum dextrose agar at $37^{\circ} \mathrm{C}$ and heat-killed, and (c) a noncommercial T. spiralis third instar larval crude antigen. Each antigen was coupled to differently marked Bio-Plex Pro Magnetic $\mathrm{COOH}$ beads $\left(10 \mu \mathrm{g} / 2.5 \times 10^{6}\right.$ beads) using an Amine Coupling Kit according to the manufacturer's instruction (Bio-Rad, Hercules, CA, USA). During the above procedure, the beads were 
protected from prolonged light exposure by covering the tubes containing them with aluminum foil.

The following one-step protocol was used after it was validated in terms of repeatability $(<10 \%$ interassay coefficient of variation $(\mathrm{CV}))$ and optimization. A total of $50 \mu \mathrm{L}$ of master mix containing approximately 3500 coupled beads for each of the three bead sets, biotinylated protein AG (Thermo Scientific, Waltham, MA, USA) at 1:500 dilution $(0.1 \mu \mathrm{L}$ per well) and $2 \mu \mathrm{g} / \mathrm{mL}$ streptavidin-phycoerythrin in dilution buffer containing $0.1 \mathrm{M}$ PBS (pH: 7.2), 1\% BSA $(w / v)$, and $0.05 \%$ Tween $20(v / v)$, were added to each well of a Bio-Plex Pro $^{\mathrm{TM}}$ flat-bottom 96-well plate. An amount of $50 \mu \mathrm{L}$ serum (diluted $1 / 25$ ) was then added (giving a final dilution of $1 / 50$ ), and plates were incubated for $2 \mathrm{~h}$ at room temperature on a shaker (600 rpm). During incubation, the flat-bottom 96-well plate was sealed and covered with aluminum foil. Beads were then washed twice with $100 \mu \mathrm{L}$ wash buffer (0.1 M PBS and $0.05 \%$ Tween 20) using the Bio-Plex Pro Wash Station (Bio-Rad), which includes a magnetic plate carrier, performing a hands-free procedure and preventing excessive bead loss during the washing step. Finally, the beads were resuspended in $100 \mu \mathrm{L}$ of dilution buffer. The bead reporter fluorescence, expressed as MFI (median fluorescence intensity), was determined with a Bio-Plex 200 (Bio-Rad) instrument that was initially calibrated and set to count 100 beads from each of three bead sets, with the DD gate values set at 7500-25,000. Specifically, the instrument uses two lasers: one distinguishes the different bead sets, and the second one measures the MFI of each bead set.

Each sample was tested in duplicate, and the average MFI calculated. On each plate, a negative control well containing $50 \mu \mathrm{L}$ of master mix and $50 \mu \mathrm{L}$ of dilution buffer was included and used to calculate the background MFI. The MFI value of each sample was determined by subtracting the background MFI from the average MFI. A positive-control serum sample of each pathogen (M. bovis, B. suis, and T. spiralis) from experimentally infected domestic pigs that were confirmed as positive using standard diagnostic methods was included in each plate, and its MFI, after subtracting the background MFI of the plate, was used for normalization of the MFI values of the sera run on different plates. The MFI normalization was performed by dividing the MFI value of each sample by the MFI value of the corresponding positive-control serum (intraplate normalization). The CV of the MFI values of the positive control serum sample was $<20 \%$ between the different plates (interplate variation). The normalized MFI values were used for statistical analysis. Both non-normalized and normalized MFI values of each serum sample of known serological status (M. bovis, B. suis, T. spiralis) are presented in the Supplementary Material S1.

\subsection{Receiver Operating Characteristic (ROC) Curve Analysis}

For each pathogen, we performed receiver operating characteristic (ROC) curve analysis in order to (i) assess the overall discriminatory power of the assay and (ii) select optimal cut-off values. For (i), we calculated the area under the curve (AUC) with trapezoids [18]. The confidence intervals for AUCs were estimated as described in [19]. For (ii), we determined cut-off values based on two selection criteria: (a) the point that maximizes Youden's J statistic [20], $J=S e+S p-1$, and (b) the point closest to the upper-left corner of the AUC plot [21]. This point corresponds to the optimal criterion $\min \left((1-S e)^{2}+(1-S p)^{2}\right)$. All analyses were carried out in $R$ [22] using the pROC package [23].

\section{Results}

The distribution of the normalized MFI values for each pathogen is shown in Figure 1. ROC curves are shown in Figure 2. The overall discriminatory power for all pathogens was high, as indicated by the AUCs, which were, in all instances, higher than 0.900 . The AUCs were 0.948 (95\% confidence interval: $0.916 ; 0.981), 0.997$ (0.989; 1.000), and 0.973 (0.937; 1.000) for M. bovis, B. suis, and T. spiralis, respectively. Further, selected cut-offs resulted, for all pathogens, in high Se and Sp values. Specifically, for TB the best cut-off value, based on maximizing Youden's index, was 0.045 , giving a Se of $0.94(0.88 ; 0.98)$ and a Sp of $0.88(0.81$; 0.93). The cut-off closest to the upper-left corner of the AUC plot was 0.034 and had a Se of 
$0.98(0.95 ; 1.00)$ and a Sp of $0.86(0.79 ; 0.92)$. For Brucella and Trichinella, the same cut-off maximized Youden's index and was closest to the upper-left corner of the AUC plot. This cut-off value was equal to 0.017 for Brucella and had a Se of $1.00(1.00 ; 1.00)$ and a Sp of $0.97(0.92 ; 0.97)$. For Trichinella, this cut-off was equal to 0.048 and had a Se of $0.90(0.76$; $1.00)$ and a Sp of $0.99(0.97 ; 1.00)$.

Specifically, the MPB83 antigen detected 63/64 of the TB seropositive wild boar, and it was negative in 91/106 TB seronegative wild boar. The B. suis 1330 antigen discriminated all Brucella seropositive wild boar (30/30) from Brucella seronegative wild boar (39/39). Finally, the T. spiralis antigen detected 19/21 Trichinella seropositive wild boar, and it was negative in 96/97 Trichinella seronegative wild boar.

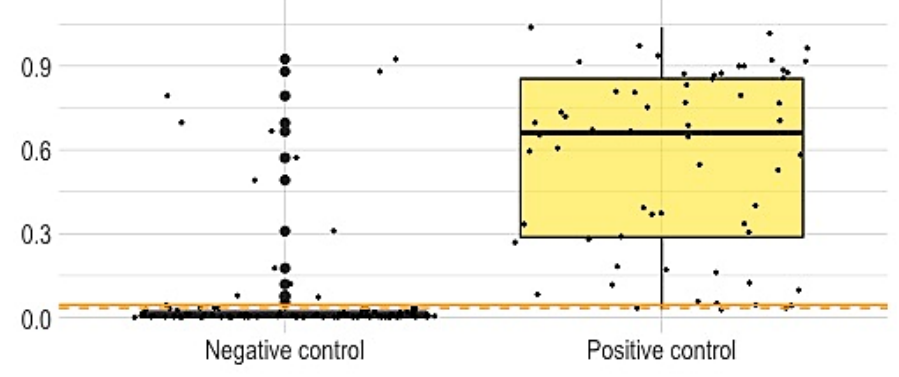

(a)

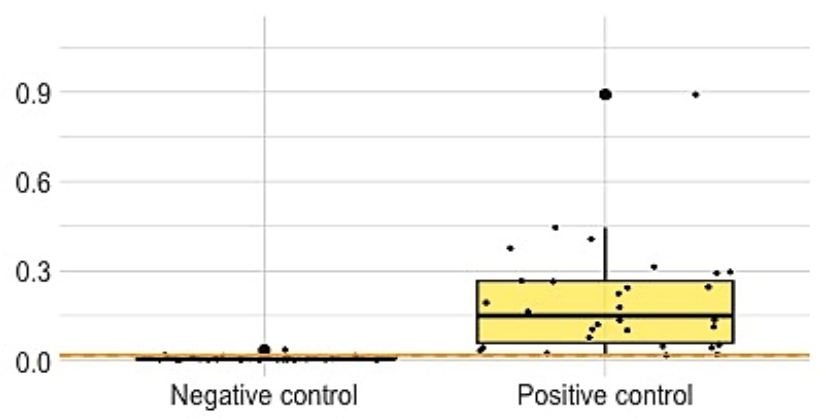

(b)

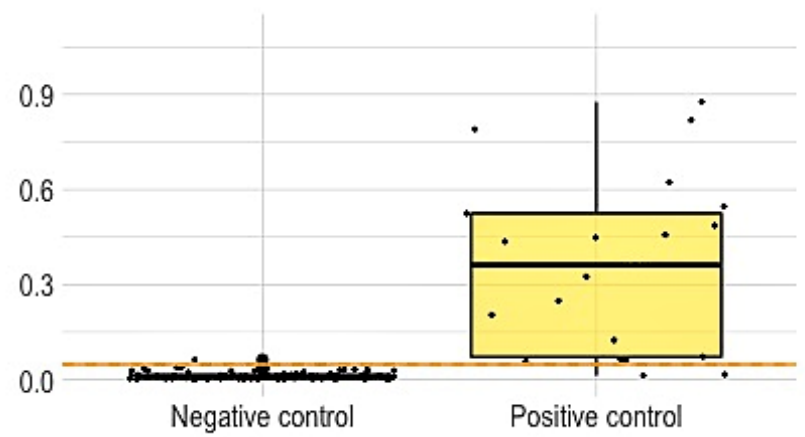

(c)

Figure 1. Distribution of the normalized MFI values for M. bovis (a), B. suis (b), and T. spiralis (c). Dots correspond to actual MFI values. Boxes represent interquartile ranges while the solid black line at the approximate center of each box is the median; the arms of each box extend to cover the central $95 \%$ of the distribution of the normalized MFI values. 


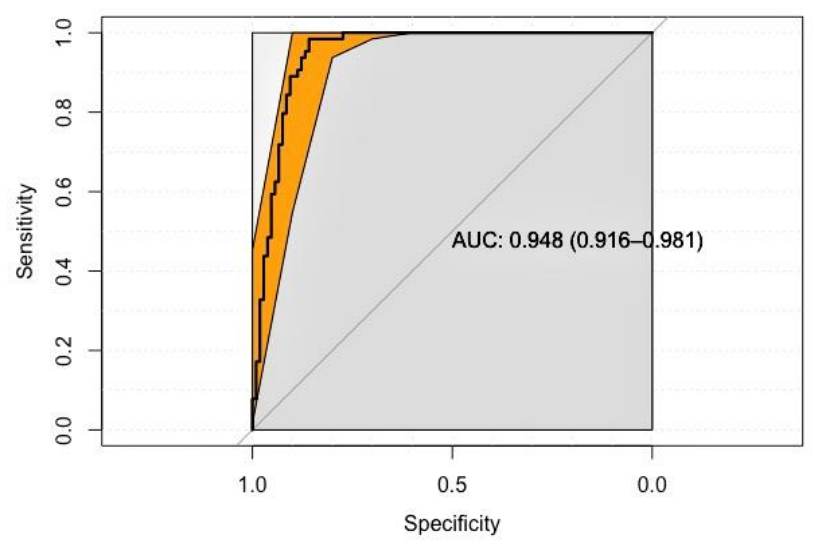

(a)

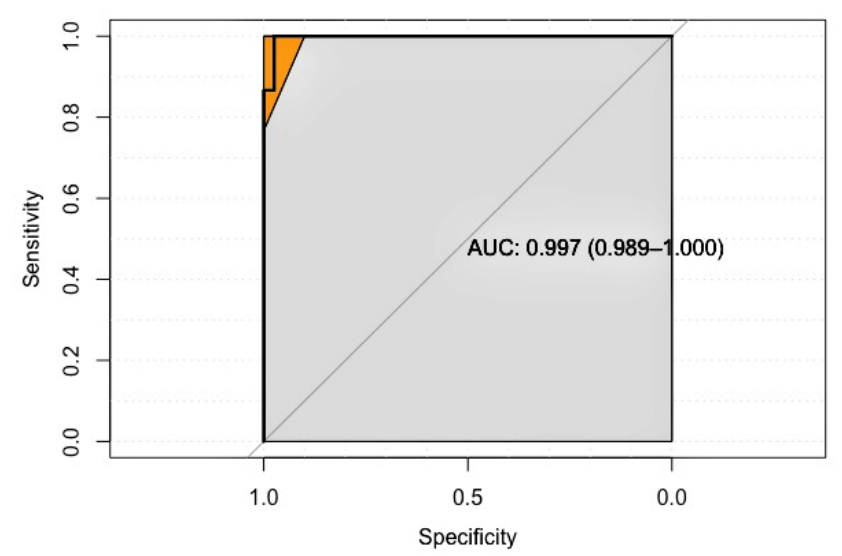

(b)

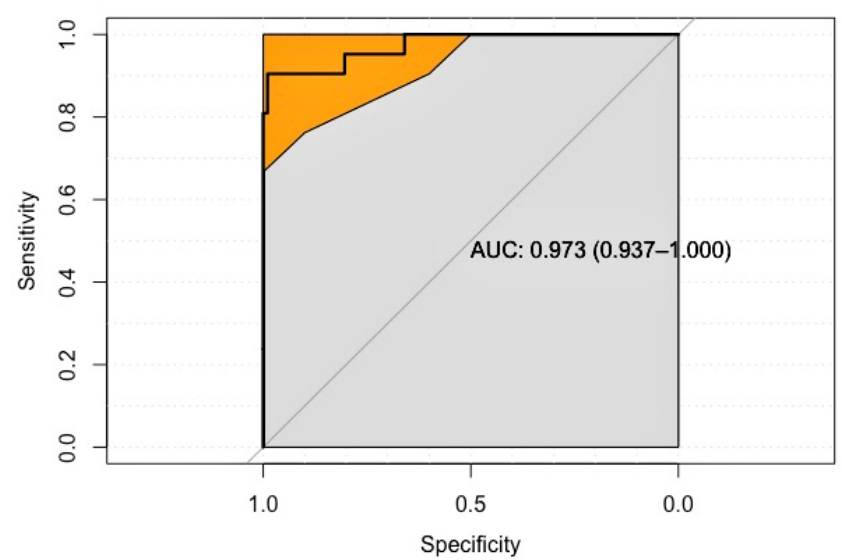

(c)

Figure 2. Plot of the receiver operating characteristic (ROC) curve analysis for M. bovis (a), B. suis (b), and T. spiralis (c).

\section{Discussion}

This study shows the diagnostic potential of a multiplex bead assay for the simultaneous detection of antibodies against M. bovis, B. suis, and T. spiralis in wild boar in a single serum sample. All AUCs were higher than 0.900 , indicating that the overall discriminatory power of all tests was high [21]. For M. bovis only, part of the distribution of the negative samples overlaps with the distribution of the positive samples, leading to cut-off values with high Se but Sp lower than 0.88 . 
Although studies in cattle propose multiantigen assays for the diagnosis of bovine tuberculosis in order to increase sensitivity [24], there is an increased risk for immunoglobulins to reach with shared antigens expressed by other bacteria, leading to cross-reactivity. The relatively early appearance of anti-MPB83 antibodies, around 4 weeks post-infection in cattle [25], the increased Se of serology using the MPB83 antigen in experimentally infected cattle and goats $[25,26]$, and the characterization of this antigen as one of the most immunodominant antigens most commonly recognized by antibodies from $M$. bovis-infected cattle, white-tailed deer, wild boar, warthogs, and badgers [27] were the reasons for the selection of this single antigen for our assay.

Several antigens have been used for the development of serological assays for the detection of antibodies against $M$. bovis in wild boar populations, giving results similar to that obtained in the present study [28]. Additionally, a recent study showed that when the MBP83 antigen is included in a serological assay for the detection of antibodies against $M$. bovis, it seems to improve the sensitivity of the assay, indicating that this antigen should be included in any serological assay developed for porcine species [29]. The diagnostic performance of a conventional ELISA for wild boar, in which the MPB83 antigen was used, showed better diagnostic performance than our assay, but using a different concentration of the antigen $(0.5 \mathrm{mg} / \mathrm{mL})$ and a different secondary antibody [30].

The whole-cell B. suis antigen used in the multiplex bead assay was selected because it contains a broad range of antigens and epitopes and it has a high O-chain content [31]. The multiplex assay discriminated efficiently between Brucella seropositive and seronegative wild boar (Se/Sp = 1.00/0.97). Although the serological tests that use smooth Brucella antigens have acceptable sensitivity, they lack specificity $[8,32]$ due to serological crossreactions between Brucella spp. and Y. enterocolitica O:9. However, the good diagnostic performance of smooth antigens in discriminating Brucella-infected from noninfected domestic pigs has been reported previously [33-35].

The selection of the E/S antigen in serological assays to differentiate Trichinella-positive from negative samples was based on reports of good diagnostic performance in serological assays, showing a Se of 0.93-0.99 and a Sp of 0.91-0.99 [36-38]. The reported usefulness of the E/S antigen to screen for trichinellosis $[39,40]$ was further demonstrated in our multiplex assay, as indicated by the high Se and Sp values.

The relatively low specificity values of the multiplex assay were to be expected, as it has been demonstrated that increases in the number of antigens used in a serological assay leads to decreases in specificity [41]. In such multiplex bead assays, cross-reactivity may occur among the different antigen-coated bead sets, leading to unspecific binding of antibodies to a wrong antigen. However, the sensitivities and specificities of all the three antigens in this assay are still good enough to suggest that they have potential for screening purposes at least, indicating that the cross-reactivity is negligible. Moreover, the study provides further proof of principle that such a multiplex approach is worthwhile.

\section{Conclusions}

Our assay is particularly valuable when one takes into account its multiplex onestep nature, which allows the screening for exposure to multiple pathogens in a single process. Furthermore, the use of conjugated protein A/G enables the assay to be used for serodiagnosis in multiple mammal species. These properties are particularly important for wildlife surveillance, where samples are often hard to acquire and frequently of limited volume, with no species-specific reagents available.

Supplementary Materials: The following are available online at https:/ / www.mdpi.com/article/ 10.3390/microorganisms9050904/s1, File S1: Non-normalized and normalized MFI values of each serum sample of known serological status (M. bovis, B. suis, and T. spiralis).

Author Contributions: Conceptualization, A.T., V.S., L.P. and C.B.; methodology, A.T., G.V., S.C., V.S., L.P. and C.B.; validation, A.T., G.V., S.C., C.G., M.B., M.S. (Marina Sofia), L.V.A., M.S. (Maria Satra), Z.A., M.K., V.S., L.P. and C.B.; formal analysis, P.K.; investigation, A.T., G.V., S.C., C.G., M.B., M.S. 
(Marina Sofia), L.V.A., M.S. (Maria Satra), Z.A., M.K., V.S., L.P. and C.B.; resources, S.C., C.G., M.B., A.G., P.B., V.S., L.P. and C.B.; data curation, A.T., S.C. and L.P.; writing-original draft preparation, A.T.; writing-review and editing, A.T., S.C., C.G., L.P. and C.B.; visualization, P.K.; supervision, V.S., L.P. and C.B.; project administration, L.P. and C.B.; funding acquisition, L.P. and C.B. All authors have read and agreed to the published version of the manuscript.

Funding: We thankfully acknowledge the financial support of the European Union Seventh Framework Programme (2007-2013) under grant agreement no. 222633 (WildTech) titled “Novel Technologies for Surveillance of Emerging and Re-emerging Infections of Wildlife".

Institutional Review Board Statement: This study is part of the European Union Seventh Framework Programme (2007-2013), a large collaboration project under grant agreement no. 222633 (Novel Technologies for Surveillance of Emerging and Re-emerging Infections of Wildlife-WildTech). All samples used in this study represent material collected by partners and other organizations for other purposes than this project as specified in deliverable D4.5/5.5 titled "Guidelines for ethical sample collection" submitted to the European Commission (26 February 2010, Dissemination Level: PP, restricted to other programme participants, including Commission Services). The wild boar serum samples were collected opportunistically (no active capture, killing, and sampling of wild animals specifically for this study were performed) from animals hunter-harvested by members of hunting federations. Thus, special approval was not necessary, and steps to ameliorate suffering were not applicable to this study. Research on animals as defined in the EU Ethics for Researchers document (European Commission, 2007, Ethics for Researchers-Facilitating Research Excellence in FP7, Luxembourg: Office for Official Publications of the European Communities, ISBN 978-92-79-05474-7) is not applicable to this study.

Informed Consent Statement: Not applicable.

Data Availability Statement: All data are presented in the manuscript and in the Supplementary Materials.

Conflicts of Interest: The authors declare no conflict of interest.

\section{References}

1. Meng, X.J.; Lindsay, D.S.; Sriranganathan, N. Wild Boars as Sources for Infectious Diseases in Livestock and Humans. Philos. Trans. R. Soc. Lond. B Biol. Sci. 2009, 364, 2697-2707. [CrossRef] [PubMed]

2. Serraino, A.; Marchetti, G.; Sanguinetti, V.; Rossi, M.C.; Zanoni, R.G.; Catozzi, L.; Bandera, A.; Dini, W.; Mignone, W.; Franzetti, F.; et al. Monitoring of Transmission of Tuberculosis between Wild Boars and Cattle: Genotypical Analysis of Strains by Molecular Epidemiology Techniques. J. Clin. Microbiol. 1999, 37, 2766-2771. [CrossRef] [PubMed]

3. Zanella, G.; Durand, B.; Hars, J.; Moutou, F.; Garin-Bastuji, B.; Duvauchelle, A.; Fermé, M.; Karoui, C.; Boschiroli, M.L. Mycobacterium Bovis in Wildlife in France. J. Wildl. Dis. 2008, 44, 99-108. [CrossRef] [PubMed]

4. Naranjo, V.; Gortazar, C.; Vicente, J.; de la Fuente, J. Evidence of the Role of European Wild Boar as a Reservoir of Mycobacterium Tuberculosis Complex. Vet. Microbiol. 2008, 127, 1-9. [CrossRef]

5. Tuberculosis (TB) ICDC. Available online: https://www.cdc.gov/tb / default.htm (accessed on 20 February 2021).

6. Cvetnic, Z.; Mitak, M.; Ocepek, M.; Lojkic, M.; Terzic, S.; Jemersic, L.; Humski, A.; Habrun, B.; Sostaric, B.; Brstilo, M.; et al. Wild Boars (Sus Scrofa) as Reservoirs of Brucella Suis Biovar 2 in Croatia. Acta Vet. Hung. 2003, 51, 465-473. [CrossRef] [PubMed]

7. Paton, N.I.; Tee, N.W.; Vu, C.K.; Teo, T.P. Visceral Abscesses Due to Brucella Suis Infection in a Retired Pig Farmer. Clin. Infect. Dis. 2001, 32, E129-E130. [CrossRef]

8. Brucellosis: OIE-World Organisation for Animal Health. Available online: https://www.oie.int/en/animal-health-in-theworld/animal-diseases/brucellosis / (accessed on 22 March 2021).

9. Muñoz, P.M.; Boadella, M.; Arnal, M.; de Miguel, M.J.; Revilla, M.; Martínez, D.; Vicente, J.; Acevedo, P.; Oleaga, A.; Ruiz-Fons, F.; et al. Spatial Distribution and Risk Factors of Brucellosis in Iberian Wild Ungulates. BMC Infect. Dis. 2010, 10, 46. [CrossRef]

10. Pozio, E. World Distribution of Trichinella Spp. Infections in Animals and Humans. Vet. Parasitol. 2007, 149, 3-21. [CrossRef]

11. Diaz, J.H.; Warren, R.J.; Oster, M.J. The Disease Ecology, Epidemiology, Clinical Manifestations, and Management of Trichinellosis Linked to Consumption of Wild Animal Meat. Wilderness Environ. Med. 2020, 31, 235-244. [CrossRef]

12. Jaroso, R.; Vicente, J.; Fernandez-de-Mera, I.G.; Aranaz, A.; Gortazar, C. Eurasian Wild Boar Response to Skin-Testing with Mycobacterial and Non-Mycobacterial Antigens. Prev. Vet. Med. 2010, 96, 211-217. [CrossRef]

13. Pollock, J.M.; Welsh, M.D.; McNair, J. Immune Responses in Bovine Tuberculosis: Towards New Strategies for the Diagnosis and Control of Disease. Vet. Immunol. Immunopathol. 2005, 108, 37-43. [CrossRef] 
14. Lilenbaum, W.; Schettini, J.C.; Souza, G.N.; Ribeiro, E.R.; Moreira, E.C.; Fonseca, L.S. Comparison between a Gamma-IFN Assay and Intradermal Tuberculin Test for the Diagnosis of Bovine Tuberculosis in Field Trials in Brazil. J. Vet. Med. Ser. B 1999, 46, 353-358. [CrossRef] [PubMed]

15. Thomas, J.; Balseiro, A.; Gortázar, C.; Risalde, M.A. Diagnosis of Tuberculosis in Wildlife: A Systematic Review. Vet. Res. 2021, 52, 31. [CrossRef] [PubMed]

16. McGiven, J.A. New Development in the Immunodiagnosis of Brucellosis in Livestock and Wildlife. Rev. Sci. Tech. 2013, 32, 163-176. [CrossRef]

17. Boadella, M.; Lyashchenko, K.; Greenwald, R.; Esfandiari, J.; Jaroso, R.; Carta, T.; Garrido, J.M.; Vicente, J.; de la Fuente, J.; Gortázar, C. Serologic Tests for Detecting Antibodies against Mycobacterium Bovis and Mycobacterium Avium Subspecies Paratuberculosis in Eurasian Wild Boar (Sus Scrofa Scrofa). J. Vet. Diagn. Investig. 2011, 23, 77-83. [CrossRef] [PubMed]

18. Fawcett, T. An Introduction to ROC Analysis. Pattern Recognit. Lett. 2006, 27, 861-874. [CrossRef]

19. DeLong, E.R.; DeLong, D.M.; Clarke-Pearson, D.L. Comparing the Areas under Two or More Correlated Receiver Operating Characteristic Curves: A Nonparametric Approach. Biometrics 1988, 44, 837-845. [CrossRef]

20. Youden, W.J. Index for Rating Diagnostic Tests. Cancer 1950, 3, 32-35. [CrossRef]

21. Greiner, M.; Sohr, D.; Göbel, P. A Modified ROC Analysis for the Selection of Cut-off Values and the Definition of Intermediate Results of Serodiagnostic Tests. J. Immunol. Methods 1995, 185, 123-132. [CrossRef]

22. R: The R Project for Statistical Computing. Available online: https:/ / www.r-project.org/ (accessed on 22 February 2021).

23. Robin, X.; Turck, N.; Hainard, A.; Tiberti, N.; Lisacek, F.; Sanchez, J.-C.; Müller, M. PROC: An Open-Source Package for R and S+ to Analyze and Compare ROC Curves. BMC Bioinform. 2011, 12, 77. [CrossRef]

24. Coad, M.; Clifford, D.; Rhodes, S.G.; Hewinson, R.G.; Vordermeier, H.M.; Whelan, A.O. Repeat Tuberculin Skin Testing Leads to Desensitisation in Naturally Infected Tuberculous Cattle Which Is Associated with Elevated Interleukin-10 and Decreased Interleukin-1 Beta Responses. Vet. Res. 2010, 41, 14. [CrossRef]

25. Waters, W.R.; Palmer, M.V.; Thacker, T.C.; Bannantine, J.P.; Vordermeier, H.M.; Hewinson, R.G.; Greenwald, R.; Esfandiari, J.; McNair, J.; Pollock, J.M.; et al. Early Antibody Responses to Experimental Mycobacterium Bovis Infection of Cattle. Clin. Vaccine Immunol. 2006, 13, 648-654. [CrossRef]

26. De Val Pérez, B.; López-Soria, S.; Nofrarías, M.; Martín, M.; Vordermeier, H.M.; Villarreal-Ramos, B.; Romera, N.; Escobar, M.; Solanes, D.; Cardona, P.-J.; et al. Experimental Model of Tuberculosis in the Domestic Goat after Endobronchial Infection with Mycobacterium Caprae. Clin. Vaccine Immunol. 2011, 18, 1872-1881. [CrossRef] [PubMed]

27. Lyashchenko, K.P.; Greenwald, R.; Esfandiari, J.; Chambers, M.A.; Vicente, J.; Gortazar, C.; Santos, N.; Correia-Neves, M.; Buddle, B.M.; Jackson, R.; et al. Animal-Side Serologic Assay for Rapid Detection of Mycobacterium Bovis Infection in Multiple Species of Free-Ranging Wildlife. Vet. Microbiol. 2008, 132, 283-292. [CrossRef] [PubMed]

28. Aurtenetxe, O.; Barral, M.; Vicente, J.; de la Fuente, J.; Gortázar, C.; Juste, R.A. Development and Validation of an Enzyme-Linked Immunosorbent Assay for Antibodies against Mycobacterium Bovis in European Wild Boar. BMC Vet. Res. 2008, 4, 43. [CrossRef] [PubMed]

29. Miller, M.A.; Gortazar, C.; Roos, E.O.; Risalde, M.A.; Johnathan-Lee, A.; Sridhara, A.A.; Lyashchenko, K.P. Serological Reactivity to MPB83 and CFP10/ESAT-6 Antigens in Three Suid Hosts of Mycobacterium Bovis Infection. Vet. Microbiol. 2019, 235, 285-288. [CrossRef]

30. García-Bocanegra, I.; Pérez de Val, B.; Arenas-Montes, A.; Paniagua, J.; Boadella, M.; Gortázar, C.; Arenas, A. Seroprevalence and Risk Factors Associated to Mycobacterium Bovis in Wild Artiodactyl Species from Southern Spain, 2006-2010. PLoS ONE 2012, 7, e34908. [CrossRef]

31. Cloeckaert, A.; Zygmunt, M.S.; Guilloteau, L.A. Brucella Abortus Vaccine Strain RB51 Produces Low Levels of M-like O-Antigen. Vaccine 2002, 20, 1820-1822. [CrossRef]

32. Olsen, S.C. Brucellosis in the United States: Role and Significance of Wildlife Reservoirs. Vaccine 2010, 28 (Suppl. 5), F73-F76. [CrossRef]

33. Paulo, P.S.; Vigliocco, A.M.; Ramondino, R.F.; Marticorena, D.; Bissi, E.; Briones, G.; Gorchs, C.; Gall, D.; Nielsen, K. Evaluation of Primary Binding Assays for Presumptive Serodiagnosis of Swine Brucellosis in Argentina. Clin. Diagn. Lab. Immunol. 2000, 7, 828-831. [CrossRef]

34. Algers, B.; Blokhuis, H.J.; Bøtner, A.; Broom, D.M.; Costa, P.; Domingo, M.; Greiner, M.; Hartung, J.; Koenen, F.; Muller-Graf, C.; et al. Porcine brucellosis (Brucella suis) scientific opinion of the panel on animal health and welfare. EFSA J. 2009, 7, 1144. [CrossRef]

35. McGiven, J.A.; Nicola, A.; Commander, N.J.; Duncombe, L.; Taylor, A.V.; Villari, S.; Dainty, A.; Thirlwall, R.; Bouzelmat, N.; Perrett, L.L.; et al. An Evaluation of the Capability of Existing and Novel Serodiagnostic Methods for Porcine Brucellosis to Reduce False Positive Serological Reactions. Vet. Microbiol. 2012, 160, 378-386. [CrossRef]

36. Murrell, K.D.; Anderson, W.R.; Schad, G.A.; Hanbury, R.D.; Kazacos, K.R.; Gamble, H.R.; Brown, J. Field Evaluation of the Enzyme-Linked Immunosorbent Assay for Swine Trichinosis: Efficacy of the Excretory-Secretory Antigen. Am. J. Vet. Res. 1986, 47, 1046-1049. [PubMed]

37. van der Leek, M.L.; Dame, J.B.; Adams, C.L.; Gillis, K.D.; Littell, R.C. Evaluation of an Enzyme-Linked Immunosorbent Assay for Diagnosis of Trichinellosis in Swine. Am. J. Vet. Res. 1992, 53, 877-882. [PubMed]

38. Bień, J. The usefulness of ELISA for diagnosis of trichinellosis in pigs and wild boars. Wiad. Parazytol. 2006, 52, 205-212. [PubMed] 
39. Kořínková, K.; Kovařčík, K.; Pavlíčková, Z.; Svoboda, M.; Koudela, B. Serological Detection of Trichinella Spiralis in Swine by ELISA (Enzyme-Linked Immunosorbent Assay) Using an Excretory-Secretory (E/S) Antigen. Parasitol. Res. 2008, 102, 1317-1320. [CrossRef] [PubMed]

40. Møller, L.N.; Petersen, E.; Gamble, H.R.; Kapel, C.M.O. Comparison of Two Antigens for Demonstration of Trichinella spp. Antibodies in Blood and Muscle Fluid of Foxes, Pigs and Wild Boars. Vet. Parasitol. 2005, 132, 81-84. [CrossRef]

41. Elshal, M.F.; McCoy, J.P. Multiplex Bead Array Assays: Performance Evaluation and Comparison of Sensitivity to ELISA. Methods 2006, 38, 317-323. [CrossRef] 